TID-4500, UC-35

Nuclear Explosions -

Pesceful Applications

Inavponoo Tadiation Iabonatory

UAIVERSITY OF CALIFORHIA

LIYERM ORE

UCRL-50897

\title{
CALCULATIONS OF FLUID STEMMING BEHAVIOR FOR CRATERING EXPERIMENTS
}

\author{
T.F. Stubbs \\ B. K. Crowley
}

\begin{abstract}
This report LEGAL NOTICE
sponsored by the prepared as an account of work

ihe Uriten by the United States Government. Neither

Camnission, Siates nor the United States nomic Ertery

their contractors, $-y$ of theís employees, nur any of

makes any warr, silbcontractors, or theis empli vees,

legal la warranty, express or implied, or assunes any

lefal lia' lity or responsioility for the accuracy, com-

provines or usefulness of any infornation, apnaratus,

prould or process disclosed, or represents that itis,

would not infringe privately owned $\mathrm{rt}_{\mathrm{t}} \mathrm{hts}$
\end{abstract}




\title{
CALCULATIONS OF FLUID STEMMING BEHAVIOR FOR CRATERING EXPERIMENTS
}

\begin{abstract}
The feasibility of using a liquid for stemming the emplacement hole in a cratering experiment is briefly investigated. A preliminary analysis is first discussed in which an analytic solution is found for a rigid cylindrical stemming plug. The $e^{f}$ fects of variations in density and Iriction of the plug are examined. A more

realistic analysis of fluid stemming, based on numerical calculations, is then discussed. This brief investigation is in no way conclusive; however, it does suggest that some of the denser liquid stemming materials could be feasible. The need for realistic experimerts and their calculationai comparisons is also indicated.
\end{abstract}

\section{Introduction}

Vertical emplacement holes for nuclear explosive devices are normally stemmed or plugged, after the device is in place, with solid materials such as sand, gravel, and concrete. When the hole has been stemmed in this way, it becomes exceedingly difficult to regain access to the device should the need arise. This problem would be mitigated if the stemming matezial were a liquid which could simply be pumped out of the hole. Such a pumpable substance would serve as "reversible stemming."

An initial attempt to numerically investigate conventional stemming was made for the Jorum experiment. ${ }^{1}$ The present work is a first attempt to numerically investigate the feasibility of using reversible (liquid) stemming cn cratering experiments.

As a crater is being explosively formed, the mound of rising earth and the stem- ming material within it are both driven upward. The important parameter to be calculated is thus the relative displacement between the mound and the stemming plug: failure obviously occurs if the steraming plug has keen ejected from the rising mound before venting would normally have occurred in a mound having no stemming penetration. In the work that follows we arbitrarily claim the stemming to be adequate if less than half the stemming material is ejected from the mound by normal vent time.

In the first section we take a simplified look at the problem of stemming by considering the equations of motion of a rigid cylindrical stemming plug. A more realistic but conservative moael is analyzed in the next section, by means of various numerical calculations and parameter studies. 


\section{Motion of a Rigid Cylindrical Stemming Plug}

Consider a circular cylinder of stemming material with radius $r$, length $L$, and density $\rho_{s^{\prime}}$. Suppose that this cylinder is surrounded by another circular cylinder of rock having density $\rho_{R}$, length $L$, and radius $R$. We will further assume both rock and stemming to behave as rigid bodies. The forces due to cavity pressure, gravity, and wall shear are diagrarnmed in Fig. 1.

The equation of motion of the rock is

$\frac{d U_{R}}{d t}=\frac{P_{c}}{L \cdot o_{R}}+\frac{2 T_{W}}{r \rho_{R}}\left[\frac{1}{(\tilde{R} / r)^{2}-1}\right]-g$,

and sirnilarly the equation of motion of the stemming is

$$
\frac{d U_{s}}{d t}=\frac{P_{c}}{L \cdot \rho_{S}}-\frac{2 T}{i \cdot \rho_{s}}-g
$$

Combining (1) and (2) we obtain the equation for the relative velocity,

$$
\begin{aligned}
\frac{d\left(U_{s}-U_{R}\right)}{d t} \equiv \frac{d U}{d t}=\frac{P_{c}}{L}\left(\frac{1}{\rho_{s}}-\frac{1}{\rho_{R}}\right) \\
-\frac{2 T_{W}}{r \rho_{R}}\left[\frac{\rho_{R}}{\rho_{S}}-\frac{1}{(R / r)^{2}-1}\right] .
\end{aligned}
$$

In these equations $P_{c}$ is the cavity pressure, $T_{w_{i}}$ is the wall shearing force given by $T_{w}=\frac{1}{2} C_{f} \rho_{s} \frac{U^{3}}{I U}$, and $C_{f}$ is known as the dynamic coefficient of friction.

Let us now postulate that the stemming plug radius is very small compared to mound dimersions; i.e.,

$$
\frac{\rho_{\mathrm{R}}}{\rho_{\mathrm{S}}} \gg \frac{1}{(\mathrm{R} / \mathrm{r})^{2}-1} \text {. }
$$

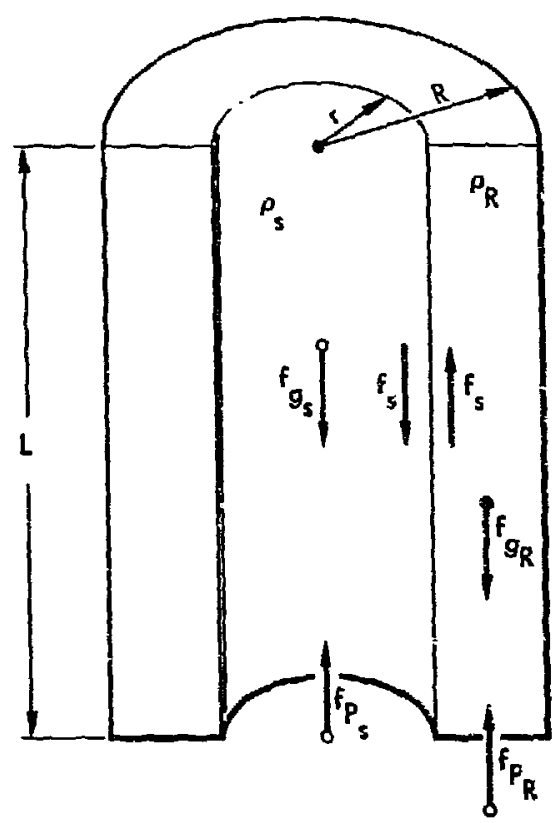

Forees

Pressure: $f_{P_{s}}=P_{c} \pi r^{2}$,

$f_{P_{R}}=P_{c} \pi\left(R^{2}-r^{2}\right)$.

Gravity: $f_{\vartheta_{5}}=-\rho_{s} g \pi r^{2} L$, $f_{g_{r}}=-\rho_{R} g \pi\left(R^{2}-r^{2}\right) L$.

Friction: $f_{s}= \pm T w^{2 \pi r L}$.

Fig. 1. Forces acting on the cylindrical stemming plug and the surrounding rock.

We then have the equation of motion

$$
\frac{d U}{d t}=\frac{P_{c}}{L}\left(\frac{1}{P_{S}}-\frac{1}{P_{R}}\right)-\frac{C_{\hat{i}}}{r^{-}} U^{2} .
$$


Assuming $P_{c}$ to be constant between $t_{0}$ and $t$, Eq. (4) integrates to

$$
U(t)=\frac{\frac{a}{\alpha} \tanh \alpha \delta t+U\left(t_{0}\right)}{1+\frac{\alpha}{a} U\left(t_{0}\right) \tanh \alpha \delta t},
$$

where

$$
\begin{aligned}
& a=\frac{P_{c}}{L}\left[\frac{1}{\rho_{s}}-\frac{1}{\rho_{R}}\right], \\
& \alpha=\sqrt{a \frac{C_{f}}{r}}, \\
& \delta t=\left(t-t_{0}\right) .
\end{aligned}
$$

The relative displacement $\Delta(t)$ is given by a further integration of Eq. (5):

$$
\begin{aligned}
\Delta(t)=\Delta\left(t_{0}\right)+\frac{r}{C_{f}} & \ln \{[\cosh \alpha \delta t \\
& \left.\left.+\frac{\alpha}{a} U\left(t_{0}\right) \sinh \alpha \delta t\right]\right\} .
\end{aligned}
$$

We have run a parameter study which simultaneously varied $\rho_{S}$ and $C_{f}$ in Eqs.(5) and (6): $1.0 \leq \rho_{s} \leq 2.25$ and $10^{-5} \leq C_{f} \leq 0.1$. Drilling fluids are availabie with density from 1.0 (water) to higher than 2. Realist:c values of $C_{f}$ are not presently known; however, 0.001 to 0.05 should span the range of expected values. Indeed, a value of $\mathrm{C}_{\mathrm{f}} \approx 0.01$ for flow in a rough pipe is indicated in Ref. 2. A radius of $1 \mathrm{~m}$ was taken for all of the stemming columns in this parameter study.

The cavity pressure history ${ }^{3}$ shown in Fig. 2 (obtained from the T-1 TENSOR calculation described in the next section) was used as a set of discrete steps in time for input to Eqs. (5) and (E). This

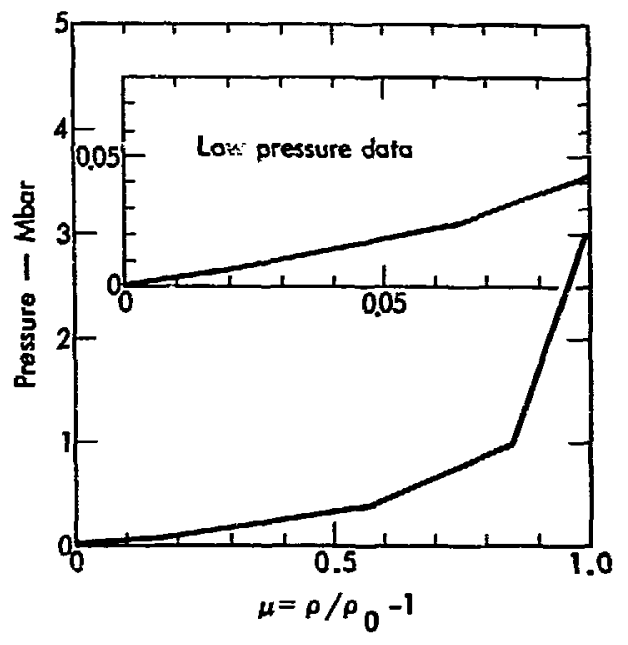

Fig. 2. Compressional equation of state of rock used in problems T-1, $\mathrm{S}-1, \mathrm{~S}-2$, and $\mathrm{P}-1$.

cavity pressure history represents a problem consisting of the relcase of 1 megaton of energy at a depth of $400 \mathrm{~m}$ in rock having a density of $2.63 \mathrm{~g} / \mathrm{cc}$.

In Table 1 we list the value of total relative displacement occurring at a time of $4 \mathrm{sec}$ (the expected breakup time of the mound) as a function of both stemming density and $C_{f}$. These data indicate that motion of the stemming piug is more sensitive to the plug's density than to wall friction. Further, the data indicate that this model is successfully stemmed for all values of $C_{f}$ when $\rho_{s}>1 .: 5$. (Remember that the requirement for adequate stemming used here is that half or less of the stemming material be extruded from the mound at normal vent time.)

Although this model is highly simplified, the results were encouraging enough to proceed to the next step in sophistication. 
Table 1. Relative displacemsnt in niêters between mound and stemming at 4 seconds after the shot.

\begin{tabular}{|c|c|c|c|c|c|}
\hline \multirow[b]{2}{*}{$c_{f}$} & \multicolumn{5}{|c|}{ Stemming density ( $\mathrm{g} / \mathrm{cc}$ ) } \\
\hline & 1.0 & 1.50 & 1.75 & 2.0 & 2.25 \\
\hline 0.00001 & 633.0 & 292.5 & 195.5 & 122.5 & 65.7 \\
\hline 0.0001 & 632.0 & 292.7 & 195.4 & 122.4 & 65.7 \\
\hline 0.0005 & 627.4 & 291.7 & 194.9 & 122.2 & 65.6 \\
\hline 0.001 & 621.7 & 290.5 & 194.4 & 122.0 & 65.5 \\
\hline 0.003 & 600.8 & 285.7 & 192.2 & 121.2 & 65.3 \\
\hline 0.006 & 573.4 & 279.0 & 189.1 & 119.9 & 54.9 \\
\hline 0.01 & 542.4 & 270.9 & 185.2 & 118.3 & 64.4 \\
\hline 0.02 & 483.3 & 253.3 & 176.5 & 114.5 & 63.3 \\
\hline 0.04 & 406.0 & 226.5 & 162.5 & 108.1 & 61.2 \\
\hline 0.06 & $355: 7$ & 207.4 & 151.4 & 102.7 & 59.3 \\
\hline 0.08 & 319.4 & 192.0 & 142.4 & 98.1 & 57.5 \\
\hline 0.10 & 291.5 & 179.5 & 134.7 & 94.1 & 56.0 \\
\hline
\end{tabular}

\section{Numerical Simulation of Stemming Behavior}

\section{PRELIMINARY CALCULATIONS}

\section{Comparison of PUFL, SOC, and TENSOR}

In order to compare the behavior of a stemming plug with that of the growing mound, it is first necessary to obtain the behavior of not only the mound but also of the driving pressure in the cavity below the mound. This has been done by the two-dimensional rock mechanics code $T^{T}{ }^{2} O^{4}$ in the problem denoted $T-1$. The medium in which the simulated explosion occurred was a hard "canai rock" whose equation of state is given in Fig. 2. 5 The energy released was $1 \mathrm{Mt}$ at a depth of $400 \mathrm{~m}$. The problem was run for the first $6 \mathrm{sec}$ of the cratering process, and the resulting cavity pressure as a function of time is given in Fig. 3.
In order to consider the effects of friction and to have the expediency of a one-dimensional calculation, the PUFL ${ }^{6}$ code was used for the reversible stemming studies discussed later. However, before performing these calculations, a comparison between the one-dimensional pipe geometry PUFL and the two-dimensional TENSOR codes on a spherically diverging material having no shear strength was needed.

To avoid running a second twodimensional TENSOR calculation, the onedimensional, spherical-geometry rock mechanics code, SOC. ${ }^{7}$ was used for the comparisons. Numereus previous comparisons of SOC and TENSOR nad been made and had given good agreement. ${ }^{8}$ Thus it was assumed that the comparison given by SOC would also be that given by 


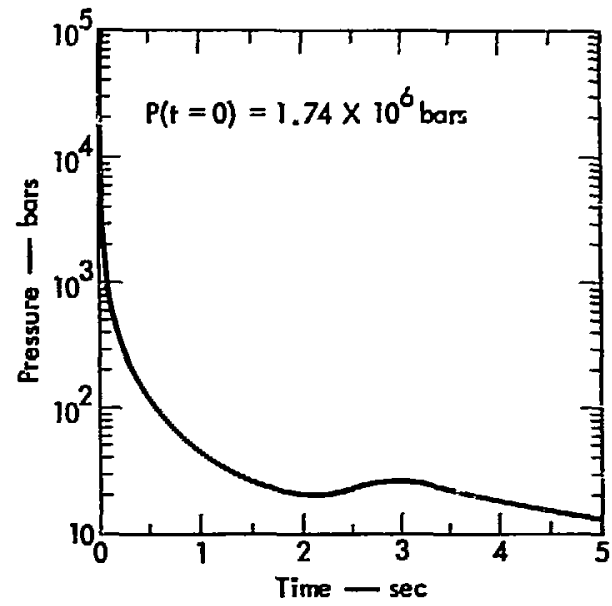

Fig. 3. Cavit pressure used as driving force for all problems considered.

TENSOR. It must be noted that the SOC problem S-1 can be compared with the TENSOR calculation only so long as every part of the mound is moving along a radius vector from the shot point. Such "spherical divergence" of the mound has been found from $T-i$ to last only for about the first $300 \mathrm{msec}$, after which it is only approximate. We thus feel that a comparison using SOC is valid up to about 300 msec.

The SOC calculation considered here, S- 1 , used the same equation of state for the rock as used in the TENSOR calculation $T-1$, except that Poisson's ratio was changed to $1 / 2$. The value of $1 / 2$ was cliosen to eliminate material strength, to allow a direct comparison with PUFL.

S-1 used the cavity pressure history given by $\mathbf{T}-1$ applied to its inner rock boundary. The PUFL problem P-1 which compares to S-1 was set up to have rigid, frictionless pipe walls with a spherically divergent cone of halfangle $1.5^{\circ}$. The working material exert- ing the pressure was a fluid having the same density and $p-\mu$ behavior as $T-1$ and S-1. The pressure history of $T-1$ was applied at the rock inner boundary.

Figure 4 shows the particle velocities in the mound as a function of radial position at $300 \mathrm{msec}$ from $\mathrm{S}-1$ and $P-1$. Figure 4 indicates the feasibility of using PUFL. on spherically diverging problems, and the favorable SOC-PUFL agreement implies a favorable TENSOR-PUFL agreement.

The close agreement seen in Fig. 4 is, of course, not surprising; the same physics is supposedly employed in the codes and the same input shouid yield the same results. This agreement does, however, give us confidence that with

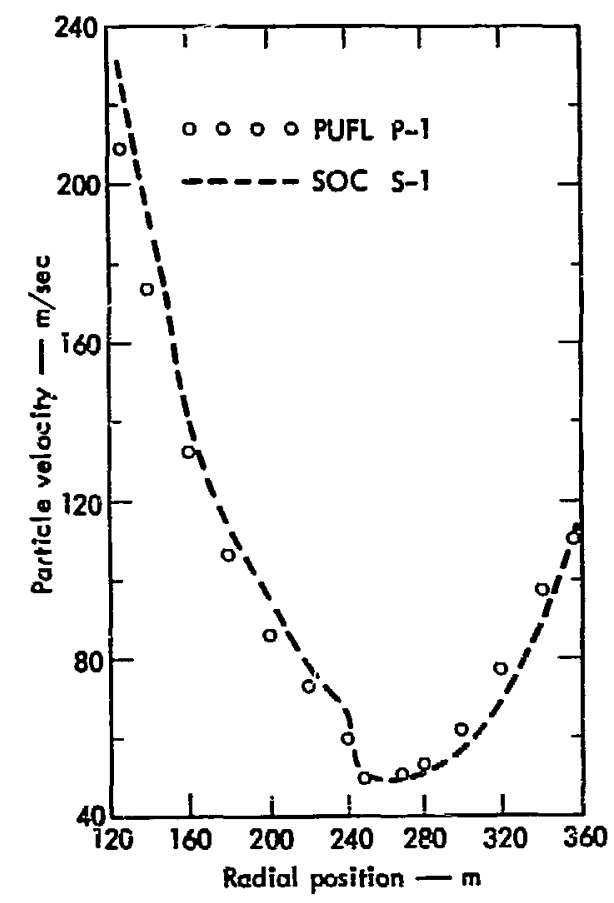

Fig. 4. Comparison of particle velocities in mound as calculated by SOC and PUFL at time of $300 \mathrm{msec}$. 
the proper boundary and initial conditions we should be able to predict with reasonable accuracy the behavior of a stemming plug that has negligible shear strength in a physically real situation using the PUFL code.

\section{Distortion of a Cylindrical Region in an Almost Spherically Divergent Mound}

In a real situation the stemming material is placed in a vertical cylindrical region rather than in the conical "pipe" used in problem P-1. As the mound develops with time this cylindrical zone is distortec by the motion of the surrounding material. The motion of material particles is roughly along a radius vector from the shot point, modificd by the maierial compressibility and the asphericity introduced by the rarefaction from the ground surface and the gas acceieration phase of mound growth. A measure of this asphericity is given by the time history of the outer boundary of the first angular zone in problem $\mathrm{T}-1$. This zone has an angular half-width of $\phi \equiv 1.5^{\circ}$.

Consider a point on this boundary (e. g.) its intersection with the surface of the gas cavity). Referring to Fig. 5 for details of notation for the following, we see that at time $t=0$ this point has the coordirates $x_{0}$ and $r_{0}=x_{0}$ tan $\phi$, and at time $t$ it has the courdinates $X\left(X_{0}, t\right)$ and $r\left(X_{0}, t\right)$. If the motion had been pure spherical divergence, the radial coordinate would have been $r_{c}\left(x_{0}, t\right)=X\left(X_{0}, \therefore\right)$ tan $\phi$. We now define an "asphericity factor" $p\left(X_{C}, \vec{r}, t\right)=$ $r\left(X_{0}, t\right) / r_{c}\left(X_{0}, t\right)=r\left(X_{0}, t\right) / X\left(X_{0}, t\right) \tan \phi_{2}$ where $r\left(X_{0}, t\right)$ is the actial radius of the ri-st TENSOR zorie.

We further postulate that for values of radial position in the vicinity of $r\left(x_{0}, t\right)$ all material particles have the same asphericity factor.

Let us now consider the motion of the point $P$ having the initial coordinates $X_{0}$, $R_{0}$ on the boundary of the cylindrical zone. If the motion were pure spherical divergence then the coordinates of this point (now at $P^{\prime}$ ) would be, at time $t, X\left(X_{0}, t\right.$ ) and $R_{c}\left(X_{0}, t\right)=X\left(X_{0}, t\right) \tan \theta$, where $\tan \theta=R_{0} / X_{0}$. By the hypothesis of the previou $\equiv$ paragraph, the true radial position of the point is giren by applying $p\left(X_{0}, \vec{r}, t\right)$ to the spherically diverging position, $R_{c^{*}}$ Thus $R\left(X_{0}, t\right)=\rho\left(X_{0}, \vec{r}, t\right) X\left(X_{0}, t\right) \tan \theta$.

Simplifying we get, finally,

$$
\begin{aligned}
R\left(X_{0}, t\right) & =r\left(X_{0}, t\right) \frac{\tan \theta}{\tan \phi} \\
& =r\left(X_{0}, t\right) \frac{R_{0}}{X_{0}} \frac{X_{0}}{r_{0}} \\
& =R_{0} \frac{r\left(X_{0}, t\right)}{r\left(X_{0}, 0\right)}
\end{aligned}
$$

Table 2 gives positions of three points on the boundary of the first angular zone as calculated in problem $T-1$. Figure 6 depicts the resulting deformation as a function of time of a cylinder initially having unit radius. These results are to be used as the time-varying pipe wall dimensions in a realistic PUFL calculation of the behavior of reversible stemming material discussed in the next section.

\section{CALCULATED BEHAVIOR OF FLUID PLUG}

Using the time-varying boundary obtained above we have run five additional 


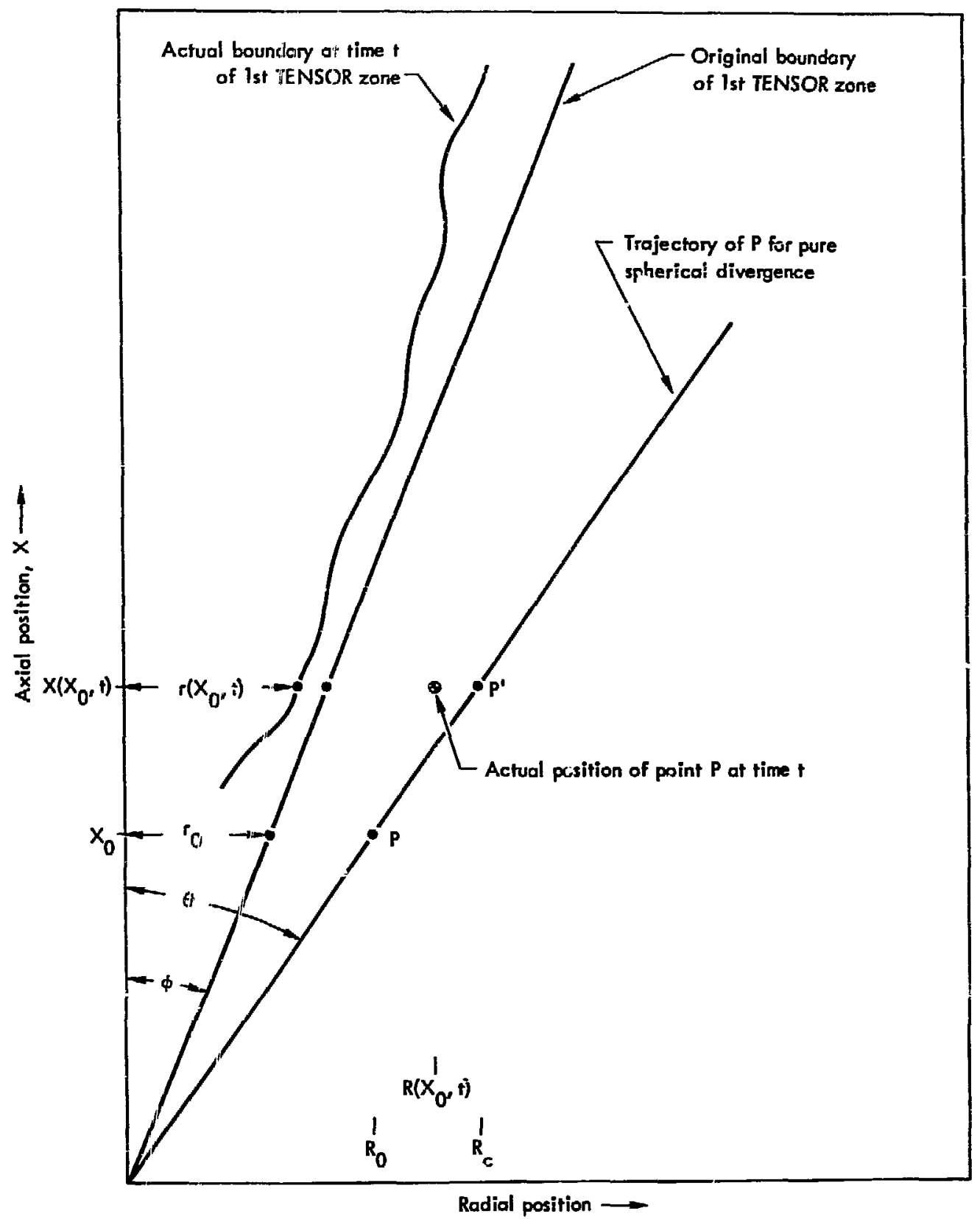

Fig. 5. Notation used in text. 


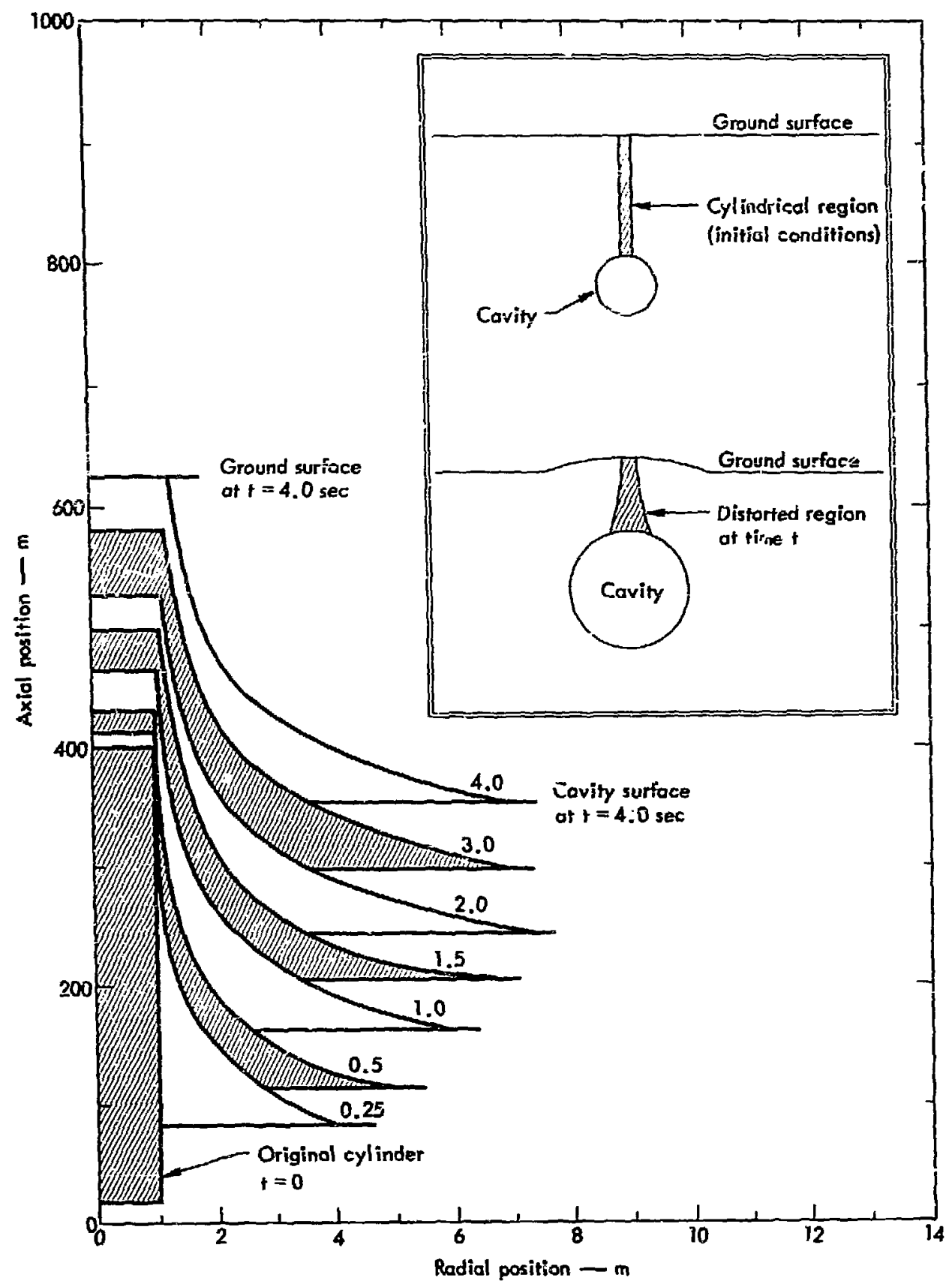

Fig. 6. Distartion of the sylindrical stemming plug during cratering as a function of time after the shot. 
Table 2. Position as a function of time for three selected points on the boundary of the first angular zone of problem $T-1$. Coordinates of the points are given in meters.

\begin{tabular}{|c|c|c|c|c|c|c|}
\hline \multirow{2}{*}{$\begin{array}{l}t \\
\text { sec }\end{array}$} & \multicolumn{2}{|c|}{ Cavity surface } & \multicolumn{2}{|c|}{ Mean axial position } & \multicolumn{2}{|c|}{ Ground surface } \\
\hline & $x\left(x_{0}, t\right)$ & $r\left(\overline{x_{0}, t}\right)$ & $X\left(X_{0}, t\right)$ & $r\left(X_{0}, t\right)$ & $\overline{x\left(x_{0}, t\right)}$ & $r\left(X_{0}, t\right)$ \\
\hline 0 & 18.5 & 0.4845 & 209.0 & 5.474 & 400.0 & 10.476 \\
\hline 0.25 & 82.1 & 1.98 & 243.0 & 6.36 & $413=0$ & 10.69 \\
\hline 0.50 & 114.7 & 2.40 & 268.3 & 7.05 & 431.3 & 10.80 \\
\hline 1.0 & 164.2 & 2.84 & 312.7 & 8.03 & 466.2 & 11.18 \\
\hline 1.5 & 207.3 & 3.21 & 357.0 & 9.07 & 498.7 & 11.56 \\
\hline 2.0 & 243.8 & 3.57 & 385.4 & 5.78 & 528.8 & 11.95 \\
\hline 3.0 & 298.0 & 3.36 & 438.9 & $\therefore .99$ & 581.6 & 12.70 \\
\hline 5.0 & 354.1 & 3.44 & 488.1 & 10.67 & 624.5 & 13.44 \\
\hline
\end{tabular}

PUFL problems labeied P-2, P-3, P-4, $P-5$, and $P-6$. The first three of these comprise a survey of the behavior of the fluid stemming plug with $C_{f}$ as a varied parameter. P-5 and P-6 were run to estimate the effect of censity on the containment characteristics of the fluid. For all of the provlems, the upper and lower boundaries of the fluid plug are considered to be free surfaces, with the lower boundary being driven by the pressure nistory given in Fig. 1.

In all cases the pressure-compressibility curve of the fluid is assumed to be that of water ${ }^{9}$ as clepicted in Fig. 7. This essumption may be in error: A high density fluid such as drilling mud is a water suspension of solids. The ffugoniot of this material may be that of water up to some pressure at which the suspended solids begin to "lock" and above which it takes on the characteristics of the solid. This would have the effect of making the stenming approximate the surrounding rock for pressures above this "locking" pressure and thus enhance the probability of stemming success. The differences between the five PUFL problems are given in Table 3
The results of these five problems are depicted in Fig. 8 where we bave incicated the position of the mass centroid of the stemming material and the positions of both the upper and lower boundaries of the surrounding rock. The immediate conclusion to be drawn from this is that water $(\rho=1,0)$ probably will rot provide adequate stemming. That is, more than half of the stemming material is ejected from the mound by vent time.

It must be semembered that the velocities calculated in PIFL are absolute with respect to a fixed working point and are not relative to the surrounding rock. PUFL calcuiates the retarding frictional force by $T_{w}=\frac{1}{2} C_{f} \rho u^{2}$ where $u$ is the

Table 3. Parameters varied in the numerical survey of the stemming characteristics of liquids.

\begin{tabular}{ccl}
\hline Problem & $\rho(\mathrm{g} / \mathrm{cc})$ & $\mathrm{C}_{\mathrm{f}}$ \\
\hline P-2 & 2.0 & 0 \\
P-3 & 2.0 & 0.002 \\
P-4 & 2.0 & 0.02 \\
P-5 & 1.0 & 0.002 \\
P-6 & 1.75 & 0.002 \\
\hline
\end{tabular}




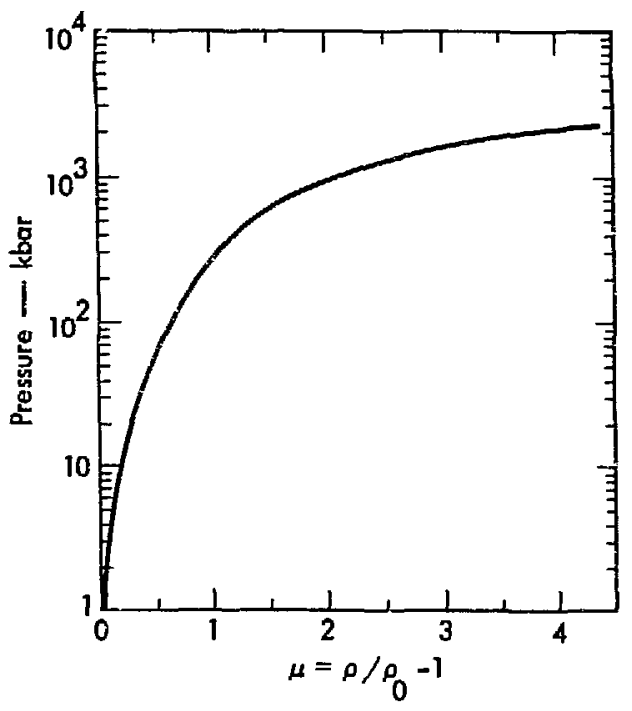

Fig. 7. Hugoniot of water $(\mu(1 \mathrm{bar})=0)$.

absolute velocity. Actually, the relative velocity (i.e., the velocity relative to the surrounding rock) should be used when calculating the retarding friction force. Since the absolutc velocity is larger than the relative velocity, for a given value of $C_{f}$ the PUFL calculations overestimate the retarding friction force.

The P-4 calculation in Fig. 8 used $C_{f}=0.01$ and clearly indicates the effect of overestimated friction. In this problem, the mass centroid of the fluid cannot keep up with the surrounding rock. A more realistic situation is seen in the $\mathrm{P}-3$ calculation where $C_{f}=0.002$. The error introduced by using the absolute velocity instead of a relative velocity when calculating the friction force could possibly be compensated for by choosing a "conservatively low" value for $\mathrm{C}_{\mathrm{f}}$. However, friction factors for this type of "flow" have not been verified by experimentai measurements. Therefore, it is not presently possible to quantitatively state what a "conservatively low" value of $\mathrm{C}_{\mathrm{f}}$ actuaily is.

The low density rock indicated in Fig. 8 arises from two very different mechanisms. When shocked to pressures greater than 150 kbar, water vaporizes upon release; and it has been assumed in $\mathrm{T}-1$ that the ruck is water-saturated. The low density rock near the cavity is just that material whic ${ }^{2}$ has been subjected to pressures greater than $150 \mathrm{kbar}$. Near the ground surface, rock is spalled off by the motion of the free surface under the influence of the shock wave. We see, in Fig. 8, the effect of the rarefaction wave in removing material from the upper portions of the mound. This reaches a maximum at

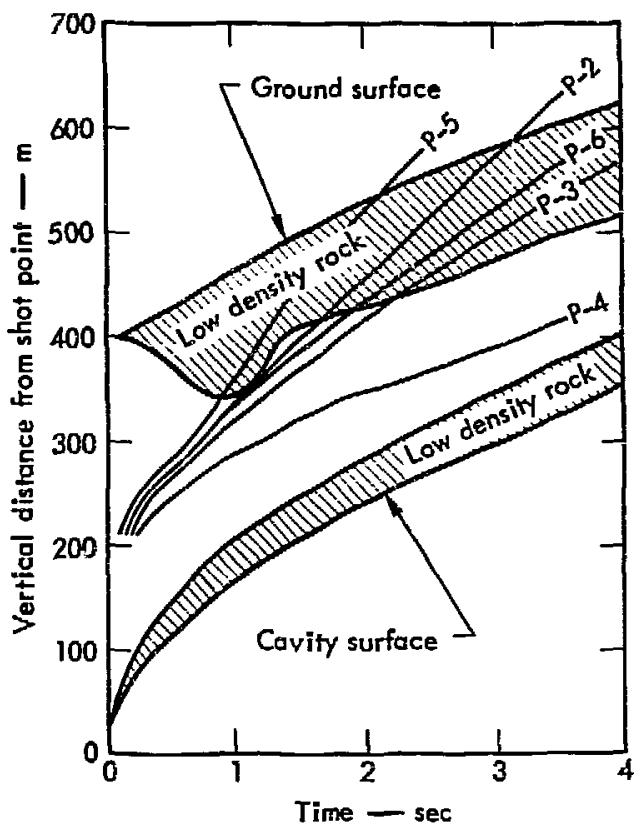

Fig. 8. Position of mass centroid of fluid stemming plug and upper and lower boundaries of surrounding rock. 
a time of about $1 / 2 \mathrm{sec}$, whereupon some recompaction takc s place. Reversible stemming material within the low-density rock regions may seep into these regions.
Hence, the stemming plug may oniy maintain its integrity and usefulness over that part of its length which is in fairly competent rock.

\section{Conclusions}

Conclusions to be drawn from this work are, for the most part, rather tenuous. First, ordinary water stemming probably will vent quite early. As the density of stemming material increases, the situation is no longer as clear. Due to the marginal results of our calculations and the fact that they are quite conservative, we may expect to achieve an adequate stemming with the denser fluids.

One of the purposes of this paper has been to indicate some of the pertinent problems involved in the use of reversible stemming. A primary need is for experimental data from which the frictional frorce and the relative motion between stemming material and mound can be obtainec. Such experiments have been suggested by Glenn. 10 He proposes to use high explosive in a series of scaled experiments which would be designed to be as similar anci calculable as possible. These proposed experiments would cover a wide range of characteristic lengths, thereby making the final extrapolation to a full nuclear test a reasonable one. Combined with the calculations, such a program could, we feel, lead to competent predictions. We also feel that competent predictions and high explosive tests will be required before reversible stemming could be used in either a cratering or a contained nuclear experiment. 


\section{References}

1. B. K. Crowley, H. D. Glenn, J. S. Kahn, and J. M. Thomsen, "Analysis of Jorum Containment, " to be published in International Journal of Rock Mechanics and Mining Science.

2. H. Schlichting, Boundary Layer Theory (McGraw-Hiil, New York, 1955), Ch. XX.

3. R. Terhune, Lawrence Radiation Laboratory, ivermore, private communication (November 1969).

4. G. Maenchen and S Sack, "The TENSOR Coce, " in Methods in Computational Physics, B. Alder, S. Fernbach, and M. Rotenberg, Eds. (Academic Press, New York, 1964), Vol. 3.

5. D. R. Stephens and E. M. Lilley, "Loading-Unloading Pressure-Volume Curves for Rocks, " paper presented at A merican Nuclear Society Topical Meeting on Engineering with Nuclear Explosives, Las Vegas, Nevada, January 14-16, 1970. (To be published in the Proceedings.)

6. B. K. Crowley, "PUFL, an 'Almost Lagrangian' Gasdynamic Calculation," J. Comp. Phys. 2, 61 (1967).

7. J. T. Cherry and F. L. Peterson, "Numerical Simulation of Stress Wave Propagation from Underground Nuclear Explosions, " paper presented at American Nuclear Society Topical Meeting on Engineering with Nuclear Explosives, Las Vegas, Nevada, January 14-16, 1970. (To be published in the Proceedings.)

8. J. T. Cherry, Lawrence Radiation Laboratory, Li'rermore, private communication (1970).

9. M. H. Rice and J. M. Walsh, "Equation of State for Water to 250 Kilobars," J. Chem. Phy. 26, 824 (1957).

10. H. D. Glenn, Lawrence Radiation Laboratory, Livermore, private communication (1970). 
